\title{
Comparison of Blood Glucose and Liver Glycogen of Larval and Adult Frogs (Rana pipiens)
}

\author{
EUGENIA S. FARRAR \\ Route No. 2, Ames, Iowa 50010 \\ B. E. FRYE \\ Department of Zoology, University of Michigan, Ann Arbor, Michigan 48104 \\ Received February 17, 1973

\begin{abstract}
Blood glucose levels are lower in tadpoles than adults. Transition to adult levels occurs during the later stages of metamorphosis, but the rise is interrupted by a brief decline in blood glucose at the beginning of metamorphic climax. Liver glycogen rises from $4.6 \%$ to $8 \%$ during larval life, falls to $1.7 \%$ at the beginning of metamorphic climax then returns to 5-7\% during late climax and in the frog. Possible mechanisms responsible for the differences in carbohydrate regulation in larval and post metamorphic amphibians, and the biological significance of the differences are briefly discussed.
\end{abstract}

In two species of amphibians, Rana clamitans (Frye, 1964) and Ambystoma tigrinum (Bartell, 1969), blood glucose levels have been shown to be lower in the larval stage of development than in the postmetamorphic juvenile and adult stages. The purpose of this paper is to report a similar metamorphic change in blood glucose levels in Rana pipiens, and to extend the observations to a comparison of liver glycogen levels before and after metamorphosis.

Tadpoles were reared from eggs of frogs collected in North Dakota. Ovulation and insemination were done by the method of Wright and Flathers (1961). Tadpoles were fed boiled spinach and were maintained at a water temperature of $20-22^{\circ}$ on a $12-\mathrm{hr}$ light:12-hr dark photoperiod. Metamorphic stages and juvenile frogs were reared from these tadpoles. Adult frogs were collected in North Dakota in July, and were acclimated in the laboratory for at least 2 weeks before use. They were maintained at an air temperature of $19^{\circ}$ on a 12 -hr light:12-hr dark photoperiod. They were force fed $1-2 \mathrm{~g}$ of beef liver twice a week, and fasted for $3-5$ days before experimental use. Animals were anesthesized with tricaine methane sulfonate prior to tissue sampling, by immersion in a $0.5 \%$ solution in the case of frogs, and a $0.03 \%$ solution in the case of tadpoles. Blood glucose was determined on $50-\mu$ l blood samples by the glucose oxidase method (Glucostat, Worthington Biochemicals). Liver glycogen was determined by the phenol sulfuric acid method for total reducing carbohydrate (Montgomery, 1957). Glycogen samples were prepared by hot $30 \% \mathrm{KOH}$ digestion of the liver samples, precipitation with 95\% ethanol (Good et al., 1933), overnight refrigeration at $5^{\circ}$, and centrifugation. The glycogen pellet thus formed was washed and centrifuged a second time in ethanol, then dissolved in distilled water for determination. In the younger tapoles, Taylor and Kollros (1946) stages IV-VI, blood and liver samples were pooled from 2-3 animals for each determination. In older animals, each sample was obtained from a single individual.

Tadpole and frog blood glucose levels are shown in Fig. 1. During the premeta-

Copyright (C) 1973 by Academic Press, Inc.

All rights of reproduction in any form reserved. 


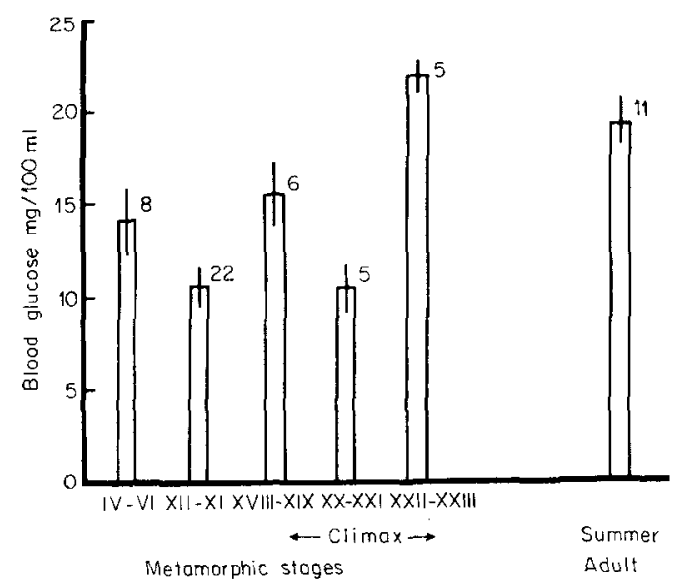

Fic. 1. Blood glucose values during larval, metamorphosing, and adult stages of the life cycle of Rana pipiens (mean \pm standard error of the mean). The number above each bar indicates the number of determinations at each stage.

morphic stages (IV-VI; XII-XV) of larval development blood glucose levels are significantly $(p \equiv 0.025)$ lower than adult levels. The greatest difference is seen during the mid-larval period (XII-XV) when the larval blood glucose levels are approximately $50 \%$ less than the adult levels. A similar magnitude of difference was seen in the larval/adult blood glucose ratios in Ambystoma tigrinum (Bartell, 1969) and Rana clamitans (Frye, 1964).

The later period of larval life is characterized by considerable fluctuation in blood glucose. Just before climax begins (XVIII-XIX) blood glucose rises to levels that are not significantly different from the adult. In early climax (XX-XXI) blood glucose drops briefly to levels as low as the early larval values, and then during later climax stages (XXII-XXIII) it rises again to adult levels. We have not examined the reasons for this variability. However, we postulate that those mechanisms which are responsible for the high blood glucose levels of the adult start to be activated at stage XVIII-XIX. The rise in blood glucose seen at that time is interrupted in early climax, when feeding first ceases but before rapid resorption of the tail and other larval tissues has begun. Subsequently, an abundance of endogenous glucose is made available by gluconeogenesis from endogenous substrates released during resorption of the tail and other tissues and blood ylucose rises again to the adult level.

Liver glycogen levels in the tadpole and the frog are shown in Fig. 2. A significant increase in glycogen occurs between the early larval stages (IV-VI) and premetamorphosis (XVIII-XIX). During early metamorphic climax a dramatic fall in glycogen occurs, from a mean of $8 \%$ of the fresh weight of the liver at stage XVIII-XIX to a mean of $1.7 \%$ at stage XX-XXI $(p<0.001)$. This fall is concomitant with the cessation of feeding which occurs at the beginning of metamorphic climax. During late climax glycogen levels rise again to values which are not significantly different from the summer adult level. Since the animals still are not feeding when the rise occurs, the rise in liver glycogen, as well as the elevation of blood glucose at this time, must result from the conversion of endogenous substrate into new carbohydrate. Liver glycogen storage during larval development and utilization during metamorphic climax have been described in anurans (Bilewicz, 1938; Hanke and Leist, 1971), but the recovery of glycogen levels in the liver during late

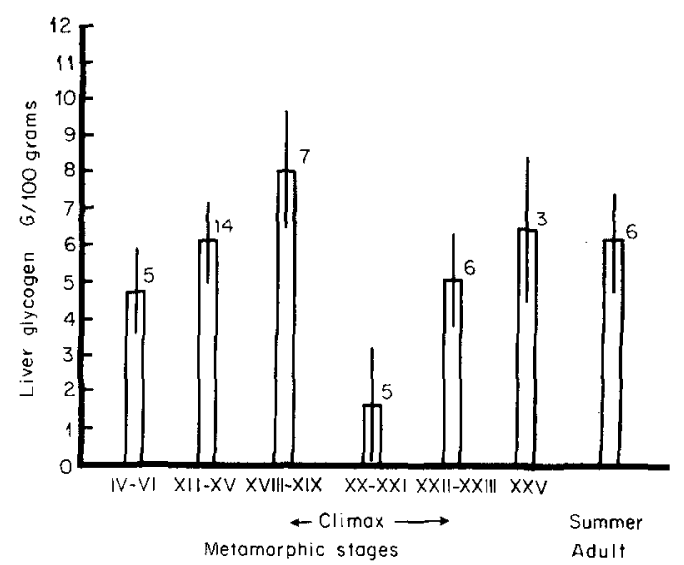

FIG. 2. Liver glycogen values during larval, metamorphosing, and adult stages of the life cycle of Rana pipiens (mean \pm standard error of the mean). The number above each bar indicates the number of determinations at each stage. 
climax has not been previously reported.

Two important questions arise from this and other studies demonstrating the existence of differences in carbohydrate regulation in larval and postmetamorphic amphibians: (1) What is the mechanism of the difference (i.e., the lower glucose values seen in larvae than in adults)? (2) What is the biological significance of the difference?

In partial answer to the first question, Bartell (1969) has shown that, in $A$. tigrinum, the larval-adult difference largely disappears after hypophysectomy of postmetamorphic animals because of a drop in the level of blood glucose of the hypophysectomized animals to near larval levels. Hypophysectomy of larvae has little effect on blood glucose. This work implicates a change in the functional status of the pituitary gland in the changes in carbohydrate regulation that occur at metamorphosis, but it does not establish which of the "hyperglycemic" hormones of the pituitary are involved. The work of Rapola (1963) and Hanke and Neumann (1972) indicates the probable involvement of ACTH and adrenal corticoids. Snyder (1970) has shown that mammalian growth hormone treatment causes a rise in blood glucose in tadpoles of $R$. pipiens, and Frye et al. (1972) have reviewed evidence which suggests that secretion of a growth hormonelike factor by the frog pituitary may be initiated or enhanced at metamorphosis. Thus, it is probable that the phenomenon described in this paper is the result of a complex of endocrine changes at metamorphosis. The observation of Medda and Frieden (1972) that the rate of total nitrogen excretion rises during metamorphosis suggests that accelerated gluconeogenesis may be one important change affecting carbohydrate levels. Induction of a number of important enzymes (notably of the urea cycle) occurs in the liver at metamorphosis (Cohen, 1970). It is possible that key hepatic enzymes involved in gluconeogenesis as well as other aspects of carbohydrate metabolism are also induced or activated at this time.

The biological significance of the change in the level of glucose regulation at metamorphosis is not known. It appears not to be related to sexual maturity, since glucose values are elevated in juvenile frogs to at least as great an extent as in the adult (Frye, 1964). Bartell's work (1969), utilizing a facultatively neotenic form of $A$. tigrinum, with sexually mature and sexually immature individuals represented in both the pre- and the postmetamorphic groups of animals, supports this conclusion. Dietary differences also appear to have been eliminated by Bartell's work since the preand the postmetamorphic Ambystoma were given the same food. Some insight into this problem may be gained by more detailed comparative studies of carbohydrate metabolism in larval and adult amphibians than have been done to date. Comparative studies are needed in particular of (1) the role of glucose as an immediate energy reserve during ambient activity, especially during brief surges of "emergency" activity; (2) the rates and processes of assimilation of foodstuffs into glucose and glycogen; and (3) the relative importance of substrates other than glucose as immediate energy reserves. Changes in gluconeogenesis would seem to be particularly adaptive in view of the change in dietary habits (from predominantly herbivore to carnivore) which occurs at metamorphosis.

\section{REFERENCES}

BaRTell, M. H. (1969). The role of the pituitary in blood glucose regulation in larval and adult salamanders, Ambystoma tigrinum. Ph.D. Dissertation, University of Michigan.

Buewicz, S. (1938). Die Änderungen des Glykogengehaltes während der Metamorphose der Kaulquappen. Biochem. Z. 297, 379-385.

CoHeN, P. P. (1970). Biochemical differentiation during amphibian metamorphosis. Science 168, 533-543.

Frye, B. E. (1964). Metamorphic changes in the blood sugar and the pancreatic islets of the frog, Rana clamitans. J. Exp. Zool. 155, 215223.

Frye, B. E., Brown, P. S., and Snyder, B. W. (1972). Effects of prolactin and somatotropin on growth and metamorphosis of amphibians. Gen. Comp. Endocrinol., Suppl. 3, 209-220.

Good, C. A., Kramer, H., and Somogyi, M. (1933). 
The determination of glycogen. J. Biol. Chem. Montgomery, R. (1957). Determination of gly$100,485-491$.

Hanke, W., ANd Leist, K. H. (1971). The effect of ACTH and corticosteroids on carbohydrate metabolism during the metabolism during the metamorphosis of Xenopus laevis. Gen. Comp. Endocinol. 16, 137-148.

Hanke, W., and Neumann, U. (1972). Carbohydrate metabolism in amphibia. Gen. Comp. Endocrinol., Suppl. 3, 198-208.

Medpa, A. K., ANd Frieden, E. (1972). Effect of prolactin and growth hormone on the ammonia excretion of bullfrog tadpoles during normal and induced metamorphosis. Gen. Comp. Endocrinol. 19, 212-217. cogen. Arch. Biochem. Biophys. 67, 378-383.

Rapola, J. (1963). The adrenal cortex and metamorphosis of Xenopus laevis Daudin. Gen. Comp. Endocrinol. 3, 412-421.

SNYDER, B. W. (1970). Physiological responses of larval and postmetamorphic Rana pipiens to growth hormone and prolactin. Ph.D. Dissertation, University of Michigan.

Taylor, A. C., aNd Kollros, J. J. (1946). Stages in the normal development of Rana pipiens larvar. Anat. Rec. 94, 7-23.

Wright, P. A., and Flathers, A. R. (1961). Facilitation of pituitary induced ovulation by progesterone in early fall. Proc. Soc. Exp. Biol. Med. 106, 346-347. 